\title{
Introduction
}

\section{What Part of "No" \\ Don't You Understand?}

Feminism in the United States as it re-emerged in the 1960s and 1970s often invoked feudal and early modern precedents to explain the persistence of heterosexual violence, and its cultural trivialization. Rape, domestic violence, and prostitution resurrected ancient presumptions, often smuggled into law itself, of "woman as property" and of chastity and reputation as a basis for a woman's familial and social status. As Gloria Steinem recently described feminist sexual politics, "it was the opposite of the idea that women were male possessions." By this anachronism it seemed that "the core" of women's oppression - physical violence - maintained its hold by denying women "ownership" of their sexuality. ${ }^{1}$ The extremely powerful, commonsense, and, in many respects, well-founded wisdom that feminism has been the historical beneficiary of liberal ideals that prize individual equality, the rule of law, and self-possession has perhaps all but stunted efforts to comprehend the complex, ambiguous legacies of the liberal tradition regarding sexuality, identity, and violence. ${ }^{2}$ Many liberal feminists as Carole Pateman notes, "appear to see only the advantages in ... making [their] demands in contractual terms, unaware that the 'individual' as owner is the fulcrum" of modern sexual inequality. In the United States this contractual relation now finds expression in terms of "choice," the right to privacy, and an emphatically proprietary view of selfhood, sex, and reproduction, casting rape or anti-abortion politics, for example, as a violation of "the right to the exclusive ownership and control of the body." ${ }^{3}$ As Gayle Rubin has noted of sexual politics, "Liberals are defensive and ... radicals almost nonexistent." ${ }^{4}$ Why has this been so? How might issues of sexual violence be contemplated outside of "defensive" liberal discourses?

In this book I seek to provide a historical analysis of the ideas of consent and coercion, a presuppositional opposition by which rights and sexual personality are governed in American culture. I seek to establish a historical foothold on the most axiomatic, and hence the most analytically elusive, terms in the liberal tradition about sexual relations. ${ }^{5}$ The tautology "yes means yes and no 
means no," a crucial corrective in the tradition of 1970 feminism's "brilliant literalism" on issues of violence, does not in fact tell us what yes and no mean. The metaphysical idea of consent inevitably accrues meaning through acts of social interpretation. As feminist theorist and historian Mary Poovey characterizes "rights," their "inherent instability must always be stabilized in practice" and made legible by the social contexts and conditions into which they are introduced. "Once exercised," she notes, "'rights' ... cannot remain abstract" but are developed by the "concrete situation in which they are embedded." 6

Sexual scientists William Masters and Virginia Johnson, for example, proclaim that "our basic concept is that any sexual practice taking place in private between consenting adults is acceptable.... Mutual consent implies that the practice is mutually enhancing [and] mutually pleasurable." 7 This definition slides from a contemporary legalism about "consenting adults" to an "implicit" message that consent means, or is evidenced in, practices that are "enhancing and pleasurable." Masters and Johnson's contention is certainly not obvious and deserves further scrutiny: it establishes pleasure and the notion of personal "enhancement" as markers of sexually free acts.

Antioch College placed an emphasis on declarations of consent when it devised an elaborate date rape policy in 1993 that stipulates that each stage of sexual encounter should be verbally consented to by a woman to a man. In this rendition, at least, a woman's verbal act of assent does the work of constituting and authenticating a sexual exchange as "free" and the result of "choice." The burden of proof, in other words, that a relation is free or coerced-as those terms are typically opposed-is imagined as a declaration. Moreover, the college's understanding of consent assumes that female subjects would not initiate a sexual encounter. This concept of consent fixes the male as the seeker and the female as the assenter, the potential victim. Hence, as Antioch elaborated a standard of consent to protect female students from date rape, the college simultaneously, and inevitably, upheld a stereotyped model of the sexual relationship between men and women. ${ }^{8}$

Under the banner of protection against sexual violence, Antioch inverted what Helen Gurley Brown, editor of Cosmopolitan magazine, had introduced in 1962 as the foundation of sexual freedom. Gurley Brown, refuting the idea that all a single woman can do when confronted with a man who "insists" is "marry him or ... say 'no,'" responded, "Where I live, there is something else a girl can say when a man 'insists.' And that is 'Yes.'" 9 If Antioch imagined a reactive female personality whose role, by the policy itself, was to consent to a man, Gurley Brown's idea of consent, as signaled by her incredulous quotes around "insists," seems to discredit the contingency of saying no, of a man's insistence as a plausible example of coercion. In effect, Antioch constituted a female subject whose normative role was to say "no," whereas Gurley Brown had earlier imagined a heroine whose normative role was to say "yes."

A great deal of intellectual energy has been expended on the meanings of yes and no. Still, Naomi Wolf concludes in her sexual coming-of-age memoir 
that "we don't know what women's consent would look like." Her assertion has clear meaning for those familiar with feminist shorthand: Wolf describes contemporary heterosexual conventions that promote dangerously inconsistent, equivocal views of female sexuality and desire, ones that leave women vulnerable to social censure or juridical disbelief when they do act sexually. But Wolf upholds an abstraction-consent-for which our contemporary context has no real referent. We don't know what consent would look like because "it" hasn't existed in ideal form and therefore hasn't existed at all. But consent has looked like and does look like what it has been socially interpreted and conceived to be. An alternative way to think about the issue historically, however, is that consent is always an interpreted idea, not an idealized abstraction. To be sure, contemporary interpretations of consent often do not define heterosexuality in empowering, just, or consistent ways for women - the point Wolf wishes to make. But casting consent as a nonexistent ideal (what would it look like?) because it has yet to be developed according to feminist values seems to erase the rich and perhaps illustrative history of the idea as a social and not a philosophical artifact. ${ }^{10}$

Defining consent and violence are profound interpretive acts for liberalism. Because the stakes are so high for women in their daily lives, feminists for decades have tried to nail down and specify what violence is. The strategy has been to position a definition of violence beyond the vagaries of interpretation, where historically women's injuries and accounts of sexual violation often have been derided and systematically represented as indications of the woman's own sexual licentiousness. In such an environment it is only logical that feminism seeks after essences, unconditional properties, of "consent," or of violence, so that these cannot be misinterpreted or talked out of view.

This effort at fixing such meanings has occurred primarily on two levels. First it has entailed the careful enumeration, in law especially, of the parameters, physical conditions, and events that can be treated as prima facie violent. ${ }^{11}$ This project focuses on the crime itself-and not on, say, the complainant's past sexual history or reputation-and on clarifying that these acts of violence occur in intimate or random relationships alike. The second level is the insistence on the literal, uninterpretable meaning of the utterances "yes" and "no," as expressed in the axiom "yes means yes and no means no." Gloria Steinem reinvoked the phrase in a 1998 editorial on President Bill Clinton's alleged harassment of White House employee and supporter Kathleen Willey. Feminists and political commentators responded with incredulity to Steinem's avowal that, since Clinton had in fact ceased his sexual advances when Willey said "no," he had not committed an act of harassment or coercion but, rather, had made a "reckless pass." Steinem's analysis conformed to a highly literal concept of "consent" (the act of saying yes) and "coercion" (lack of respect for the act of saying no). Her formulation, as critics noted, was in fact awkwardly and excessively literal: it seemed uninterested in pronounced disparities of power and did not capture the social context of the encounter. ${ }^{12}$ 
As evident in Steinem's example, the need to define women's agency-to have "no" respected as a transparent and literal assertion of will-has strange effects on the status of "yes," or authentic consent. From a feminist perspective "yes means yes" seems to occlude sources of coercion or pressure short of physical harm - whether fear or anticipation of violence, desire to avoid unpleasant but nonviolent consequences, lack of desire, or desire to please produced in the larger cultural context. Would "yes" under these circumstances really "mean yes," that is, denote a choice made in genuinely free circumstances between social peers? And if it does not denote this kind of choice, can it be seen as a free or accurate expression of a woman's intent or will? Would verbal consent signal a "genuine" choice in a larger social context of sexual inequality and male power? There are forms of coercion or even violence in addition to physical risk that literal, or fixed, parameters will not contain, or accommodate. Once interpretive pressure is exerted on the word yes, its commonsense clarity evaporates. For as obvious as the word appears, it staggers under the weight of hidden complexities.

The representatives at the United Nations Conference on Women in Beijing in 1994 surely hoped to evade controversy over what "sexual rights" might imply when crafting their platform. They jettisoned the phrase in favor of something presumably less provocative: "The human rights of women include their right to have control over and decide freely and responsibly on matters related to their sexuality . . . free of coercion, discrimination and violence." Revealingly, an American delegate paraphrased the statement as an affirmation "that a woman has the right to say 'no.'" Participants crafted the statement to sidestep contentious interpretations provoked by a phrase like "sexual rights" by using presumably more basic terms like "yes" and "no." Yet certainly "coercion" and "decid[ing] freely" can be interpreted in many ways. A reasonable observer might categorize economic duress in Thailand that leads to sexual barter as a form of coercion rather than a choice made under admittedly extreme and bad circumstances; others might contend that familial pressures or traditional forms of patriarchy constitute valid conditions of coercion even if they do not involve physical battery. There does not seem to be a way, in short, for feminists to avoid the interpretive process by burying implied meanings more deeply into a commonsense vocabulary of yes and no. ${ }^{13}$

Consent and coercion ${ }^{14}$ in the examples above and in what follows are enduringly important terms: I do not seek to discredit their value for being interpretively malleable. ${ }^{15}$ Rather I hope to demonstrate the instabilities and meanings embedded in terms historians and feminists often take as "foundational," 16 to jar new insights into what scholars, feminists, or activists imply when using the terms. This approach helps us explain and uncover the "submerged" or "hidden grammar" that "underlies observable practices or conscious discourse." Focused neither on "ideas nor the socioeconomic foundations of societies," the history of mentalités is one that seeks to understand what is "conceived and felt" on the deepest levels of meaning, how the basic 
categories organizing experience are "labeled, grouped together or valued separately in different or even contradictory ways," across historical contexts. ${ }^{17}$

In this book I consider what the idea of consent has meant historically in the U.S., and how social relationships have been constituted or changed as the meaning has changed. What types of relationships have been designated as authentic or legitimate examples of the "convergence of wills" that consent, etymologically, denotes? What contexts, types of relationships or social conditions have been thought to vitiate "real" consent, and why? In what follows I delineate the logic of consent and coercion, the alignment of properties and qualities that made them intelligible at key moments in American history. This book seeks out the dominant idiom of sexual violence in context and does not survey all of its expressions at each moment. It identifies tropes through which sexual violence and consent were brought into sharp focus. As Mary Poovey notes, those issues that are constituted as "problems" at any historical moment are "particularly important because they mark the limits of ideological certainty." 18 All of the tropes I discuss - seduction, abduction, white slavery, arranged marriage, interracial sexuality, and interracial rape-reveal that apparently similar events were understood as acts of "violence" or "choice" in revealingly distinct, yet sometimes contradictory, ways at different times.

This book examines differences in how ideas of consent and violence were formed and re-formed in order to explore the context for today's debate about sexual rights and violence. The chapters to follow contemplate how heterosexual violence comes to appear a private and not political matter; how sex and power come to appear oppositional, with violence apportioned (before the revisions of 1970 seminism) to the personal sphere of "sex" rather than "power"; how the idioms by which sexual violence is handled-for example, our complicated incredulity toward the "victim," our distrust in the very notion of "sexual violence" - developed. Most important, they consider how female sexual will has been defined in a liberal culture rhetorically committed both to individual equality qua "sameness" before law and to the preservation of basic sex difference.

Slogans such as "yes means yes and no means no," as cognates of the liberal tradition, have not necessarily illuminated the problems of sexual power endemic to the liberal tradition itself. I aim at a re-reading of historical political thought concerning sexual violence insofar as it identifies key feminist concepts - for example, the right to privacy - as an ambiguous legacy and not simply a remedy to sexual injustice.

There is much to learn concerning social relationships generally once the implied meanings of sexual consent are exposed. The opposition of consent to violence is a rich object for historical analysis because it is a concept that underwrites the three dominant social relations of liberal culture: it is relevant to the meaning of sexual freedom; it shapes ideas of citizenship as defined through consent to a "social contract"; and in a market economy driven by ideologies of free contract it contributes centrally to the assumed legitimacy of 
a labor relation. Carole Pateman recommends more analysis of these intersections, noting that "the relation of consent in everyday life to the postulated consent of the individual to the liberal democratic state remains unexplained," as does women's "ambiguous status" as "individuals." 19 Pateman argues that "writers on consent link 'consent,' 'freedom,' and 'equality," but fail to explore the relationship between liberal ideals of consent and patriarchy-or, one might add, its historical specificity. Because consent is the soul of liberalism's social practices, and figures prominently in the legitimation of its social roles, it might reveal, if taken as an object of historical study itself, some of the deeply felt yet analytically elusive interdependencies - between sex and class, race and citizenship, sex and race-of enduring interest to U.S. historians.

I argue throughout this book - against the idea of "sexuality" as a subdisciplinary theme or topic-that the deployment of consent or violence in one type of relationship necessarily affects and is modified with reference to other social "contracts" inherent to citizenship and labor. ${ }^{20}$ When seduction trials emphasized sexual consent as "proven" in women's illicit yet profitable "bargains" with their seducers, these trials conjugated the woman's sexual consent with a classic liberal ideology that defined individualism as freedom of exchange in the property of self-even, perhaps, in the immoral goods of chastity or virtue. When "white slavery" designated sexual commerce as a prima facie violence - a relationship impossible to choose-it modified the idea of a "free" labor contract as well. The modernization of heterosexuality in the first "sexual revolution" of the early twentieth century, similarly, came to be defined in relation to debates about race, citizenship, and the meaning of the "social contract." 21

Because the liberal tradition itself is tremendously complex, and internally inconsistent, some of these chapters describe the restaging, in different moments and to different effects, of contradictions that are in fact immanent in liberal thought, rather than unique to one historical juncture. For example, I comment on the fascinating, chronic conflict in American liberal practice between viewing the feme sole, the single woman, as an "ordinary individual" idealized in liberal theory as one who is not marked by sex difference-or an "extraordinary woman," who diverges from the normal subjectivity assigned to neuter individuals. ${ }^{22}$

A second overarching historical argument-developed in all three sections of this book - concerns the history of liberal culture and mentality in the United States. Although framed as a battle between liberals and conservatives on the New Right, the politics of the 1990s that coalesced around the "Contract with America" stage a contest between two forms - classic and modern-of one liberal tradition. The classic liberal view, espoused by conservatives, proposes in many respects a return to laissez-faire ideologies of the late nineteenth century, which interpreted the citizen's "freedom" as the "freedom" to compete in a comparatively unregulated economy, and to forge commercial transactions without the "imposition of the will of the government." To recon- 
cile this laissez-faire view with their impositional social policies regulating sexuality and reproduction is to identify economic rather than personal noninterference as the more meaningful site of "freedom" for citizens in classic liberal cultures. In contrast, modern liberalism has encouraged greater federal regulation over economic relations (crystallized in the war on poverty and the welfare state) and minimal regulation over sexual, procreative relations, as in the growth of the "right to privacy" in the 196os. Today's liberals see as inherently violent the "invasion" by the federal government of the sexual body and sexual relations, but do not discredit economic intervention and aid (through welfare, especially) as acts of "imposition" on otherwise free citizens.

I am attempting to illuminate a historical process by which the culture of classic liberalism in postbellum nineteenth-century America shifted to a culture of modern liberalism in the early twentieth century. As Judith Shklar proposes, liberal cultures must continually redraft - and then respect- "a boundary between ... the personal and the public. ... This is not historically a permanent or unalterable boundary," and it is one purpose of my book to trace how the idea of the private person, in John Stuart Mill's term, was transformed. ${ }^{23}$ Although modern liberalism would not reach its fullest articulation until the 1970s, its cultural logic and presuppositions were established decades earlier. The shift from classic to modern liberal visions of "freedom" required monumental revisions of what social relations should be protected in "the right to be let alone," a phrase put into play in 1880 by Thomas Cooley, a legal scholar. The shift entailed, for example, reintroducing the "free labor contract" in the early twentieth century as a legitimate site for federal regulation, and tentatively installing "personal" relations or the "sexual contract," in turn, as a site for deeper privacy and personal autonomy. I argue throughout that the historical process of moving from classic to modern liberalism has occurred in part through the mobilization of "violence" and "consent," particularly as they apply to sexual relations. Because the naming of an action as "violent" stipulates it a trespass against a subject's integrity, it necessarily modifies a culture's concept of normal subjectivity. Although discourses about seduction and white slavery elaborated the "extraordinary" character of woman, they also necessarily commented on and modified the ordinariness of the autonomous individual. I concentrate on the single woman, or feme sole, precisely because she is the figure who presents the greatest trouble for a liberal culture rhetorically committed to individualism and gender-neutral "equality" yet structured, as social histories have shown us, by sex difference. Hence, this book considers not only how sexual thought and subjectivity were modified by the American culture of liberalism, but how that liberal tradition - especially its shift from a classic to modern form-was itself modified in part by charged discourses of intimate, sexual violation.

The right to privacy, as Jane Gaines has written, is an "exceptionally" American idea. ${ }^{24}$ Debates about heterosexuality and the problem of sexual violence oscillate between these two versions of the liberal tradition, or two renditions 
of the "private self," with the effect of dampening efforts to conceptualize sexual justice outside of the liberal grammar altogether. This is unfortunate, because platitudinous rhetorics of "choice," privacy, and consent among mainstream feminists in their 1990 rendition no longer capture or compellingly describe subtleties of sexual power that feminism hopes to redress. By illuminating obfuscations of power evident in framing historically personal freedoms according to residually laissez-faire liberal ideas (among others, the body as property, the assumed discrete convergence of equal qua same wills in sexual relations, a belief in nonintervention and the freedom to be "let alone," and, of course, a pure and simple literal standard of consent), I seek to stimulate new interest in sexual rights and identity outside the syntax of liberalism in its twentieth-century forms. 